\title{
Non-dispersive selective extraction of germanium from fly ash leachates using membrane-based processes
}

\author{
Hossein Kamran Haghighi ${ }^{a}$, Mehdi Irannajad $\mathbb{1}^{a}$, Agustin Fortuny ${ }^{b}$, and Ana Maria Sastre ${ }^{c}$ \\ aDepartment of Mining and Metallurgical Engineering, Amirkabir University of Technology, Tehran, Iran; ${ }^{b}$ Department of Chemical \\ Engineering, Universitat Politècnica de Catalunya, EPSEVG, Vilanova i la Geltrú, Spain; 'Department of Chemical Engineering, Universitat \\ Politècnica de Catalunya, ESTEIB, Barcelona, Spain
}

\section{ABSTRACT}

Non-dispersive selective extraction of Ge(IV) tartrates was carried out from simulated fly ash solutions containing heavy metals through supported liquid membranes (SLM). The optimum transport was obtained using a PTFE membrane containing Alamine $3365 \% \mathrm{v} / \mathrm{v}$ in the condition of tartaric acid $2.76 \mathrm{mmol} / \mathrm{L}$ and $\mathrm{HCl} 1 \mathrm{~mol} / \mathrm{L}$ in feed and strip phases, respectively. Under this condition, a hollow fiber (HF) SLM experiment was conducted. The results showed that this system could transport germanium from the feed to the strip phase so much faster than the flat sheet (FS) SLM system. The rate of transport through HFSLMs is comparable to dispersive extractions.

Abbreviation: A: Effective area of the membrane $\left(\mathrm{cm}^{2}\right)$; BDL: Below detection limit; $C_{\mathrm{f}}$ : Feed concentration (mg/L); $\mathrm{C}_{\mathrm{t}}$ : Initial concentration (mg/L); D: Distribution coefficient; ELM: Emulasion liquid membranes; FSSLM: Flat sheet supported liquid membrane; HF: Hollow fiber; LLX: Liquidliquid extraction; P: Permeation coefficient $(\mathrm{m} / \mathrm{h})$; PTFE: Poly tetra fluoro ethylene; PVDF: Polyvinylidene difluoride; $\mathrm{T}$ : Tartrate species $\left(\mathrm{C}_{4} \mathrm{H}_{4} \mathrm{O}_{6}\right)$; $\mathrm{T}$ : Temperature $(\mathrm{K}) ; \% \mathrm{~T}$ :Germanium transport effeciency; V: Volume of feed solution $\left(\mathrm{cm}^{3}\right)$; t: time (h); $\eta$ : Viscosity (P.s (c.P)); k: Boltzmann constant; $r$ : Ionic radius of species; $\tau$ : Tortuosity of the membrane; $\rho$ : Porosity; $a$ : Separation factor.

\section{ARTICLE HISTORY}

Received 16 May 2018

Accepted 29 November 2018

\section{KEYWORDS}

Supported liquid membrane; non-dispersive extraction; germanium; fly ash; heavy metals

\section{Introduction}

Various forms of germanium have extensive applications. It can be used in photodetectors (pure form), high refraction glass (as $\mathrm{GeO}_{2}$ ), etc. Since the chemical purity of germanium is essential in its application, the recovery, separation, and purification of germanium is a significant issue. Fly ashes and zinc ores are the main resources of germanium. Fly ashes are important in terms of germanium content because $500 \mathrm{mt}$ is their estimated amount having an average germanium composition of $7.8 \mathrm{~g} / \mathrm{t} .{ }^{[1]}$ Thus, $3,900 \mathrm{t}$ of germanium can be recovered from these resources. This signified the importance of investigating the separation of germanium from simulated fly ash leach solutions. Germanium in coal gasification fly ashes can be present as a water-soluble compound in oxide and sulfide forms. ${ }^{[2]}$ One of the complexities in fly ashes is the presence of heavy metals. ${ }^{[3,4]}$ The concentration of zinc in fly ashes is commonly more than that of other heavy metals. For instance, the composition of zinc, nickel, and cadmium in fly ashes studied by Liu and colleagues $^{[3]}$ is 3288,187 , and $29.4 \mathrm{mg} / \mathrm{kg}$, respectively.
The existence of impurities such as heavy metals in these resources has focused the efforts on the separation of germanium from these impurities. ${ }^{[5]}$ There are a number of metallurgical processes for the separation of germanium from coal fly ashes. ${ }^{[6-9]}$ Among these methods, hydrometallurgical processes have some advantages such as low energy consumptions, lowtemperature emissions, suitability for the treatment of low-pure materials, etc. ${ }^{[10,11]}$ Liquid-liquid extraction is a regular method used to separate germanium from various solutions. Various types of liquid-liquid extraction (LLX) systems using different organic extractants in different mediums have been studied for the extraction and separation of germanium.

The supported liquid membrane (SLM) technique is a technique having a mechanism similar to LLX. In SLM processes, ion species are extracted and transported by an extractant which has impregnated a flat sheet membrane. Despite an LLX system, the extraction and strip processes in SLM cells are carried out in a single system. ${ }^{[12]}$ Considerable selectivity, operative easiness, low energy consumption, and low extractant usage have converted this technique into a cost- 
effective process. ${ }^{[13]}$ However, flat sheet SLM systems have been faced with challenges in industrial usages such as maintenance issues. ${ }^{[14]}$ On the other hand, a hollow fiber SLM system is based on non-dispersive solvent extraction, merging solvent extraction and flat sheet SLM advantages. In this study, the effective area of HFSLM is 127,000 times more than that of FSSLM. Therefore, it can be expected that the transport rate in an HFSLM is comparable to solvent extraction. These advantages have spread the use of HFSLM in industrial works. ${ }^{[15]}$ These processes can be reasonably used for treating low concentration solutions. ${ }^{[16]}$ The application of SLM in the separation of various metals has been carried out ${ }^{[17]}$; although, there is a dearth of investigations on the transport of germanium through the membranes.

Since extractants play important roles in the SLM system, their characterization is important. The extractants used to extract germanium can be classified into three categories. The first group includes cationic exchanger extractants, such as KELEX $100^{[18]}$, LIX $63^{[18]}$, Ionquest $801^{[19]}$, and Cyanex $301^{[20]}$ which extract cationic species of germanium and the second one is anion exchangers such as tri-n-octylamine TOA, which can extract germanium anionic complexes. ${ }^{[5,21]}$ In addition, the third group extracts neutral forms of germanium such as Cyanex 923. ${ }^{[20]}$ Various membrane systems have been used to extract germanium from the aqueous medium. One of these systems used is the ion exchange membrane such as $\mathrm{RX}-1^{[22,23]}$, functional porous hollow-fiber membranes ${ }^{[24]}$ and polysulfone. ${ }^{[25]}$ The mechanism of these membranes is similar to ion exchange resins. The other types are liquid membrane systems which are classified into several groups. However, only emulsion liquid membranes (ELM) and supported liquid membranes (SLM) have been used to transport germanium from aqueous solutions. Tutkun et al. ${ }^{[26]}$ used ECA 4360J as a surfactant, STA90 NS and Escaid 110 as the solvents, and KELEX 100 as a carrier in an ELM system. They used this system to permeate germanium from a sulfuric acid leach solution of zinc plant residue to the strip phase containing $\mathrm{NaOH}$. In another study, an ELM containing C5-7 and P204 (an extractant with a similar structure to D2EHPA) was used to transport germanium from a sulfuric acid medium to $\mathrm{NH}_{4} \mathrm{~F} .{ }^{[27]}$ Bis (2-ethylhexyl) sulfosuccinate sodium salt as an anionic surfactant was used to form a microemulsion liquid membrane with n-heptane and n-butanol as diluents and N235 as the carrier. ${ }^{[28]} \mathrm{N} 235$ is an amine extractant which can extract anionic species from solutions. In the aforementioned study, tartaric acid was used to convert germanium to anionic tartrate species which can be transported by N235. The other systems are supported liquid membranes. Only three systems were used to transport germanium through flat sheet supported liquid membranes. In these systems, $\mathrm{TOA}^{[29]}$, Alamine $336^{[30]}$, and Cyanex $301^{[31]}$ were used to transport germanium from tartaric acid and nitric acid solutions. In the TOA-SLM system, germanium tartrate was transported from a solution through the polytetrafluoroethylene (PTFE) membrane. In addition, a mass transfer model was obtained based on experimental data. The $\mathrm{pH}$ of feed solutions, carrier concentration, germanium concentration, and $\mathrm{HCl}$ concentration in the strip phase were the parameters investigated. As a result, the highest transport was obtained at a $\mathrm{pH}$ of 3 , TOA $40 \%$ $\mathrm{v} / \mathrm{v}$, and $\mathrm{HCl}$ concentration of $3 \mathrm{~mol} / \mathrm{L}$. In a study published by the authors of the present study, mathematical models resulted in calculating the constant $\left(\mathrm{K}_{\text {ext }}\right)$ of germanium extraction by Alamine 336 and mass transfer and diffusion coefficients for the germanium facilitated transport through the supported liquid membrane containing Alamine 336. ${ }^{[30]}$ In this study, only the Alamine 336 concentration effect was investigated on the extraction and transport of germanium. The principle of the modeling is also founded on this effect. In addition, the hollow fiber transport has not been studied. Cyanex 301 is another carrier used to transport germanium from the nitric acid medium across a PTFE membrane. The effect of the feed solution $\mathrm{pH}$ and concentrations of germanium, Cyanex 301, and sulfuric acid in the strip solution were studied in the mentioned paper. At the condition of $\mathrm{pH} \mathrm{1.5,} \mathrm{Ge} \mathrm{of}$ $40 \mathrm{mg} / \mathrm{L}$, Cyanex 301 of $1.18 \mathrm{~mol} / \mathrm{L}$, and $\mathrm{H}_{2} \mathrm{SO}_{4}$ of $400 \mathrm{~g} / \mathrm{L}$, the maximum transport was achieved. In the aforementioned SLM studies, the studies focused on the only transport of germanium and no effort was made to separate germanium from other species. Furthermore, the need for further investigations on transporting germanium through HFSLM and the comparison to FSSLM systems is felt.

In this research, an FSSLM process was investigated to separate germanium from a simulated neutral aqueous solution containing heavy metals. In this study, zinc, nickel, cobalt, and cadmium were selected as impurities in simulated coal gasification fly ash leach solutions. The polytetrafluoroethylene membrane (PTFE) and an organic extractant namely tri-octyl /decyl amine (Alamine 336) as a carrier were used in this system. Chemical parameters such as Alamine 336, tartaric acid, germanium, and strip phase concentrations were examined to understand their effects on the germanium transport and permeability. Finally, an HFSLM system was developed to separate germanium from an aqueous solution under the condition obtained 
from FSSLM results. In addition, the HFSLM system was compared to an LLX system.

\section{Experimental}

\section{Materials}

Alamine 336 from Cognis (now part of BASF), Germany was used as an extractant/carrier. It is a mixture of tri C810 alkyl amines. ${ }^{[32]}$ Its average molecular weight is $353.67 \mathrm{~g} / \mathrm{mol}$ with a density of $818 \mathrm{~kg} / \mathrm{m}^{3}$. Kerosene and 1-decanol as diluents were supplied by SigmaAldrich and Merck, respectively. A stock solution containing germanium, cadmium, cobalt, nickel, and zinc ions were prepared by dissolving $\mathrm{GeO}_{2}, \mathrm{ZnSO}_{4} .7 \mathrm{H}_{2} \mathrm{O}$, $\mathrm{CdSO}_{4}, \quad \mathrm{CoSO}_{4} \cdot \mathrm{H}_{2} \mathrm{O}, \quad \mathrm{NiSO}_{4} \cdot 6 \mathrm{H}_{2} \mathrm{O}$ (Aldrich A.C.S. Reagent) in pure distilled water. This solution can be considered as a simulated solution obtained after water leaching of coal gasification fly ashes containing germanium. These metals can be considered as important impurities of fly ash leach liquors. Moreover, since Alamine 336 has anionic exchanger behavior, the tartaric acid reagent from Merck, Germany was used to form an anionic compound of germanium.

\section{Solution chemistry of germanium}

Various forms of germanium species in a neutral solution has been characterized in the literature as $\mathrm{H}_{2} \mathrm{GeO}_{3}{ }^{[21]}$, $\mathrm{GeO}_{2} \cdot \mathrm{H}_{2} \mathrm{O}^{[28]}$, and $\mathrm{Ge}(\mathrm{OH})_{4} \cdot{ }^{[33]}$ According to the mentioned references, $\mathrm{GeOH}_{4}$ is a more probable and reliable species, which can be present in the neutral pHs. In addition, the reaction between $\mathrm{GeOH}_{4}$ and tartaric acid results in the formation of anionic germanium tartrates. It is noticed that after adding tartaric acid (depending on the amount of addition) the $\mathrm{pH}$ of the neutral solution descends to a range of $2-4 . \mathrm{Ge}(\mathrm{OH})_{2}(\mathrm{HT})^{-}$and $\mathrm{Ge}(\mathrm{OH})_{2}(\mathrm{~T})^{2-}$ have been characterized as predominant species at $\mathrm{pHs}<2$ and $\mathrm{pHs}>2$, respectively. ${ }^{[34]}$ In addition, $\mathrm{Ge}(\mathrm{OH})_{2}(\mathrm{~T})_{2}{ }^{2-}$ species are reported to be predominant at neutral $\mathrm{pHs} .{ }^{[30,35,36]}$ One of the ways to know the number of extractant molecules that can extract germanium species is the slope analysis. In this regard, the plot of $\log (\mathrm{D})$ as a function of $\log \left[\mathrm{R}_{3} \mathrm{NH}^{+} \mathrm{Cl}^{-}\right]_{(\text {org })}$ was plotted elsewhere. ${ }^{[30]}$ The slope of the plot showed that 2 moles of the extractant participated in the extraction reaction. In addition, according to charge balancing and the mentioned slope, the charge of germanium anionic species extracted by Alamine 336 should be 2 as $\mathrm{Ge}(\mathrm{OH})_{2}(\mathrm{~T})^{2-} \operatorname{orGe}(\mathrm{OH})_{2}(\mathrm{~T})_{2}{ }^{2-}$. Consequently, at the working pHs of this study, $\mathrm{Ge}(\mathrm{OH})_{2}(T)^{2-}$ has been proposed as predominant species. Thus, an overall reaction for the formation of germanium anionic species using tartaric acid can be written as Eq. $(1)^{[34]}$ :

$$
\begin{aligned}
& 2\left[\mathrm{R}_{3} \mathrm{NH}^{+} \mathrm{Cl}^{-}\right]_{(\text {org })}+\mathrm{Ge}(\mathrm{OH})_{2}(\mathrm{~T})^{2-}{ }_{(a q)} \\
& \quad \Leftrightarrow\left[\left(\mathrm{R}_{3} \mathrm{NH}^{+}\right)_{2} \mathrm{Ge}(\mathrm{OH})_{2}(\mathrm{~T})^{2-}\right]_{(\text {org })}+2 \mathrm{Cl}^{-}{ }_{(a q)}
\end{aligned}
$$

\section{Methods}

\section{Transport of germanium through FSSLM}

The FSSLM experiments were conducted in a twosection cell where the feed phase with a volume of $220 \mathrm{~mL}$ was separated from the strip phase $(220 \mathrm{~mL})$ by a supported liquid membrane with an effective membrane area of $11 \mathrm{~cm}^{2}$ (Fig. 1). In the FSSLM cells, the feed and strip phases were mechanically stirred with a speed of $1,200 \mathrm{rpm}$ at room temperature $\left(22 \pm 1^{\circ} \mathrm{C}\right)$ by Plexiglas mixers to keep the concentration at the bulk phase. To prepare the membrane containing the carrier, first the desired volume of Alamine 336 was dissolved in kerosene and 1-decanol to obtain a particular concentration of the carrier, and then the membrane was soaked in the desired carrier for a few hours. The soaked membrane was then taken followed by rinsing with pure distilled water to remove additional carriers. Finally, the membrane was put in the membrane placement between two cells (see Fig. 1). Two types of membranes were used in this study. Millipore Durapore membranes with the materials of poly tetra fluoro ethylene (PTFE) and polyvinylidene difluoride (PVDF) were used in this study. Table 1 shows the characteristics of these membranes. The behavior of these membranes was compared in terms of the permeation of ions.

Permeation coefficient $\mathrm{P}(\mathrm{cm} / \mathrm{h})$ through the membranes were found by calculating the slopes of the plots constructed by $-\frac{V}{A} \ln \left(C_{f} / C_{f . t}\right)$ as a function of time according to Eq. (2):

$$
\ln \left(C_{f} / C_{f . t}\right)=-\frac{A P t}{V}
$$

Where $\mathrm{C}_{\mathrm{f}}, \mathrm{C}_{\mathrm{t}}, \mathrm{A}$, and $\mathrm{V}$ represent the feed concentration, initial concentration, effective area of the membrane, and volume of the feed solution, respectively. During the experiments, samples of feed and receiving phases $(0.5 \mathrm{~mL})$ were taken at desired times for determining the concentration of ions using inductively coupled plasma atomic emission spectroscopy (Agilent, USA).

\section{Transport of germanium by hollow fiber supported liquid membrane (HFSLM) system}

In order to improve the performance of the FSSLM system, another type of SLM system, namely the hollow fiber supported liquid membrane (HFSLM) technique, was applied. Since it was predicted that the transport 


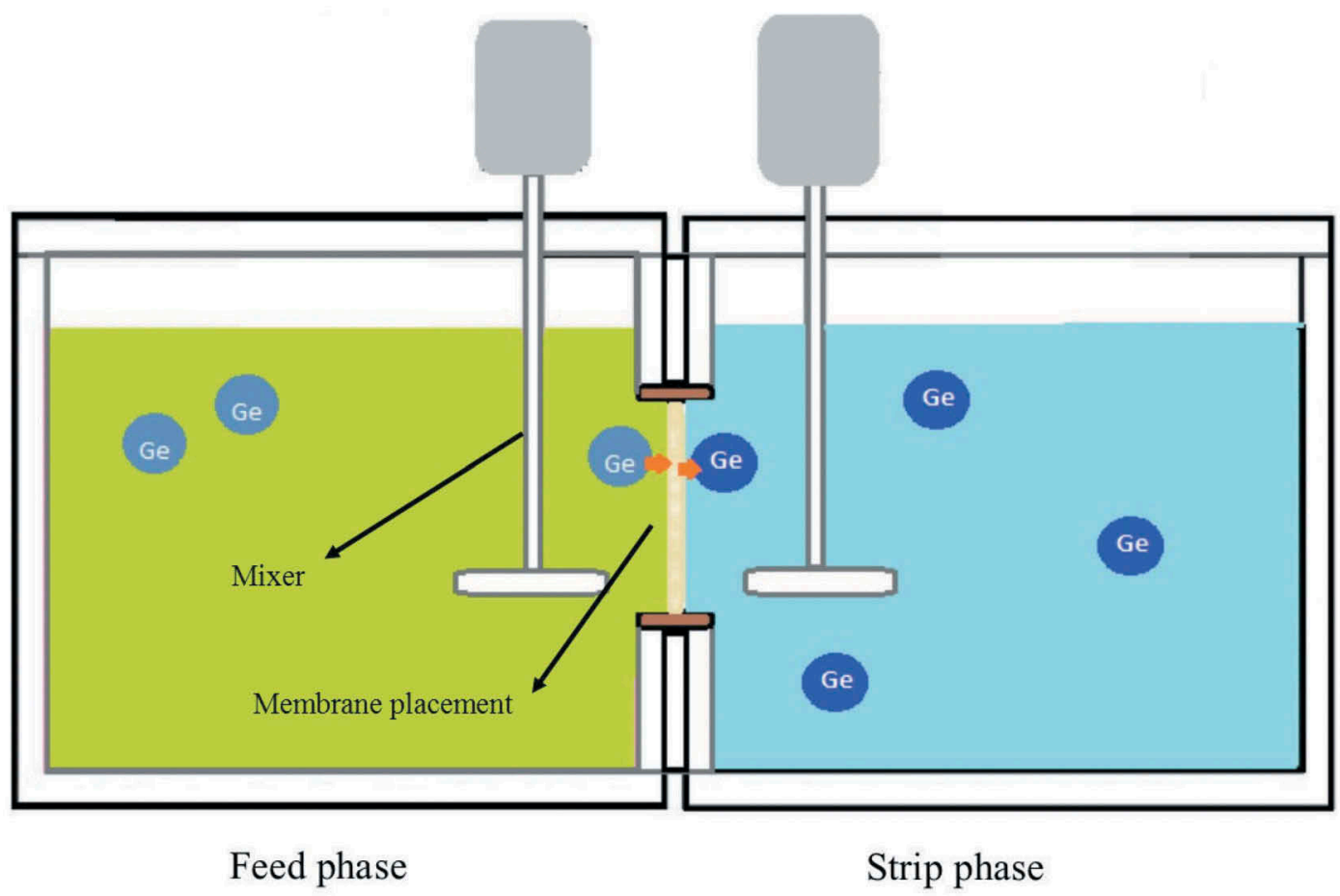

Figure 1. Schematic illustration of FSSLM used in the research.

Table 1. Characteristics of flat sheet membranes used in the current study.

\begin{tabular}{cccccc}
\hline Type & Series & $\begin{array}{c}\text { Pore size } \\
(\mu \mathrm{m})\end{array}$ & $\begin{array}{c}\text { Porosity } \\
(\%)\end{array}$ & $\begin{array}{c}\text { Thickness } \\
(\mu \mathrm{m})\end{array}$ & $\begin{array}{c}\text { Diameter } \\
(\mu \mathrm{m})\end{array}$ \\
\hline PTFE & FHLP series & 0.45 & 85 & 50 & 47 \\
PVDF & HVHP04700 & 0.45 & 75 & 125 & 47 \\
PVDF & HVHP04700 & 0.22 & 75 & 125 & 47 \\
\hline
\end{tabular}

rate of germanium through this system was high, the minimum concentration of Alamine $336(5 \% \mathrm{v} / \mathrm{v})$ as the carrier was selected for the experiment. This organic carrier was dispersed in an $\mathrm{HCl}$ strip solution with a volume of $500 \mathrm{~mL}$ forming a pseudo emulsion. The emulsion was agitated with a magnetic agitator. The module used in this study was a G-501 contactor purchased from Liqui-Cel, the USA with the characteristics illustrated in Table 2. The pseudo emulsion was circulated from the strip container to the lumen side of the module with a flow rate of $23 \mathrm{~L} / \mathrm{h}$ using an external gear pump (Micropump ${ }^{\oplus}$, GJ Series, US). This resulted in a constant organic supply in the membrane pores. ${ }^{[37]}$ In addition, the feed phase with a volume of $2 \mathrm{~L}$ was circulated in the shell side with a flow rate of $28 \mathrm{~L} / \mathrm{h}$ using another external gear pump with the aforementioned property. In order to prevent diffusing the organic carrier across the pores into the feed phase, a small pressure variance was applied during the tests. Since the feed phase volume was 4 times the strip phase volume, the concentration ratio of the strip to the feed would be 4 . The schematic illustration of the HFSLM system used in the research was seen in Fig. 2.

\section{Result and discussion}

\section{Transport measurement}

In the FSSLM system, the transport of ions through SLM is equivalent to the simultaneous extraction and stripping in an LLX system. Since there are five ions in the system of this study, the identification of the extraction and stripping reactions taken place in the membrane interfaces is significant. To understand these reactions and the optimized conditions for the selective transport of germanium species, a series of experiments were conducted in various concentrations of Alamine 336, tartaric acid, germanium in the feed phase, and $\mathrm{HCl}$ in the strip phase.

Table 2. Characteristics of the hollow fiber membrane used in the current study.

\begin{tabular}{|c|c|c|c|c|c|c|c|c|}
\hline Type & Series & Material & Surface Area $\left(\mathrm{m}^{2}\right)$ & Diameter $(\mathrm{cm})$ & $\begin{array}{l}\text { Length } \\
(\mathrm{cm})\end{array}$ & $\begin{array}{c}\text { Housing pressure } \\
\text { rating }\left(\mathrm{Kg} / \mathrm{cm}^{2}\right)\end{array}$ & Porosity (\%) & Flow rate range $\left(\mathrm{m}^{3} / \mathrm{hr}\right)$ \\
\hline Liqui-Cel & G-501 & $\begin{array}{l}\text { Polypropylene/ } \\
\text { polyethylene }\end{array}$ & 1.4 & 8 & 28 & 8.4 & 40 & $0.16-1.8$ \\
\hline
\end{tabular}




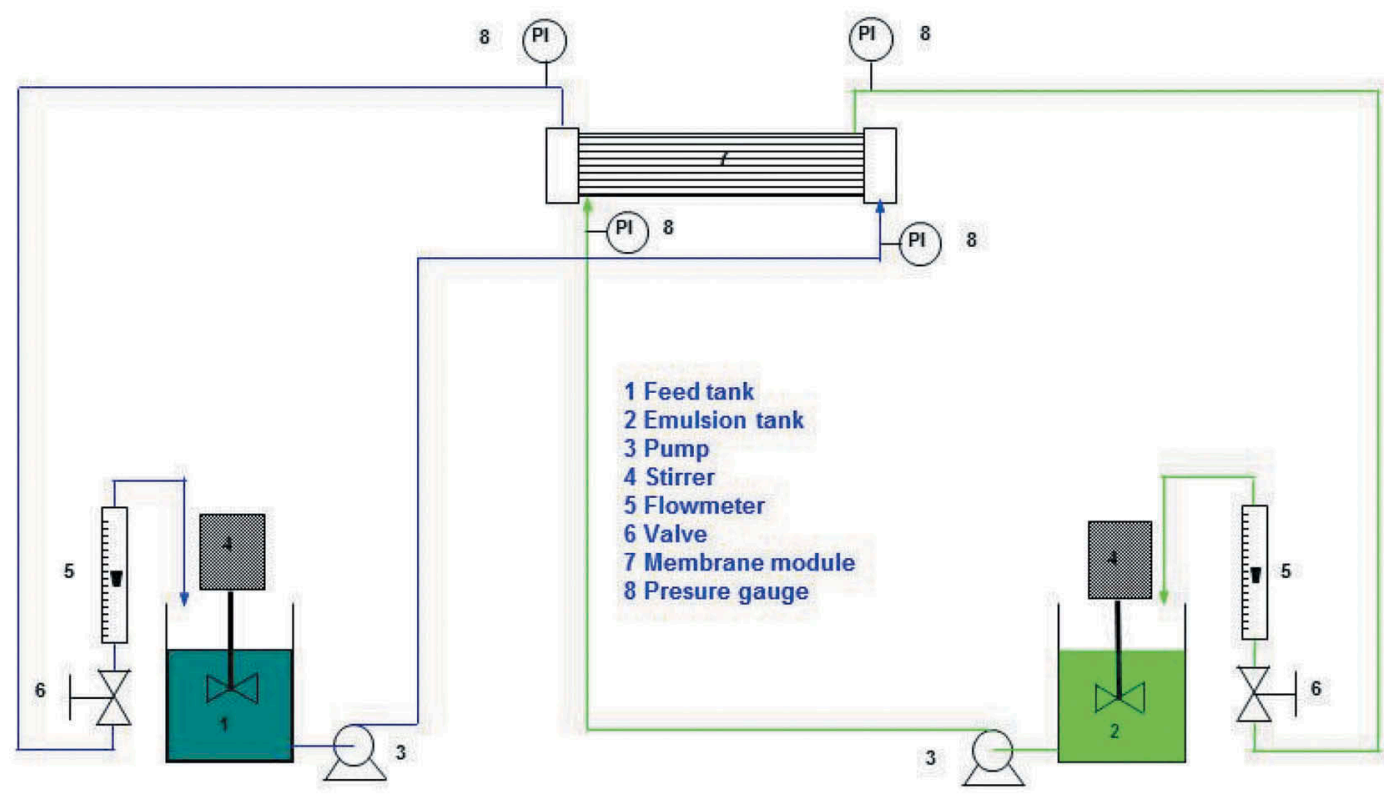

Figure 2. Schematic illustration of HFSLM used in the research.

\section{Effect of carrier (Alamine 336) concentration}

There is a direct relationship between the transport of ions through a supported liquid membrane and the carrier concentration. ${ }^{[38,39]}$ In order to find the effect of Alamine 336 as a carrier on the germanium permeation, its concentration was varied in a range of $5-35 \% \mathrm{v} / \mathrm{v}$. In all the experiments, the concentration of $\mathrm{Ge}, \mathrm{Ni}, \mathrm{Cd}$, and $\mathrm{Co}$ in the feed phase was kept at $100 \mathrm{mg} / \mathrm{L}$ and the $\mathrm{Zn}$ concentration was maintained at $1,000 \mathrm{mg} / \mathrm{L}$. Furthermore, the amount of tartaric acid added to the feed phase was equal to two times the amount of germanium in the feed phase $(2.76 \mathrm{mmol} / \mathrm{L})$. The $\mathrm{HCl}$ concentration was set at $1 \mathrm{~mol} / \mathrm{L}$ in the strip phase.

The plots of $-\frac{A}{V} \ln \left(C_{f .0} / C_{f . t}\right)$ as a function of $\mathrm{t}$ were plotted for various Alamine 336 concentrations (Fig. 3). According to these plots, germanium permeation coefficients can be determined. These coefficients were plotted for various concentrations of Alamine 336 as shown in Fig. 4. It was observed that the germanium permeation increased from 2.87 to $6.56 \mathrm{~cm} / \mathrm{h}$ with an enhancement of Alamine 336 up to $15.0 \% \mathrm{v} / \mathrm{v}$. However, with a further increase in the carrier concentration, the permeation reduced to $5.26 \mathrm{~cm} / \mathrm{h}$ and then followed a fair straight manner up to $35 \%$ and reached $5.90 \mathrm{~cm} / \mathrm{h}$ (see the trend line in Fig. 4). The preliminary enhancement of the transport rate may be due to a rise in the diffusion factor (D) when Alamine 336 increases in the membrane. ${ }^{[38]}$ This enhancement is equal to a higher concentration of germanium and carrier complexes at the feed-membrane interface resulting in enhancement of the transport rate. Furthermore, the further decrease in the transport rate is probably due to the enhancement of the viscosity and the conductivity of Alamine 336 as well as an increase in the membrane resistance. ${ }^{[38,40]}$ With respect to the inverse relative of the permeability and viscosity, this decrease can be reasonable. ${ }^{[41]}$ According to the Stokes-Einstein equation $\left(D=\frac{\kappa T}{6 \pi \eta r}\right)$, $\mathrm{D}$ has an inverse relation with viscosity $(\eta)$. In this equation, $\mathrm{T}, \kappa$, and $\mathrm{r}$ represent temperature $(\mathrm{K})$, Boltzmann constant, and ionic radius of species. In the liquid-liquid extraction process, it was seen that with an increase of the extractant concentration in the organic phase, the extraction efficiency enhanced due to the formation of the germanium-extractant complex. Hence, it was expected that this manner occurred in the SLM process because of the formation of this complex in the feed phase-liquid membrane interface. This enhancement of the complexes could improve the driving force for the permeation through the liquid membrane. However, it was experimentally observed that the viscosity of the carrier is more significant than the increase of the mentioned complexes in the interface. The dynamic viscosity of the carrier enhances from 1.68 to $27.10 \mathrm{cP}$ by increasing the concentration of Alamine 336 from 5 up to $40 \% \mathrm{v} / \mathrm{v}$. Therefore, an enhancement of viscosity results in a decrease in the germanium flux. Similar to an LLX system, apparently at higher carrier concentration, the flux should increase; however, the simultaneous enhancement of viscosity results in a diffusivity decrease of germanium-Alamine 336 complexes. ${ }^{[38]}$ This manner can be 

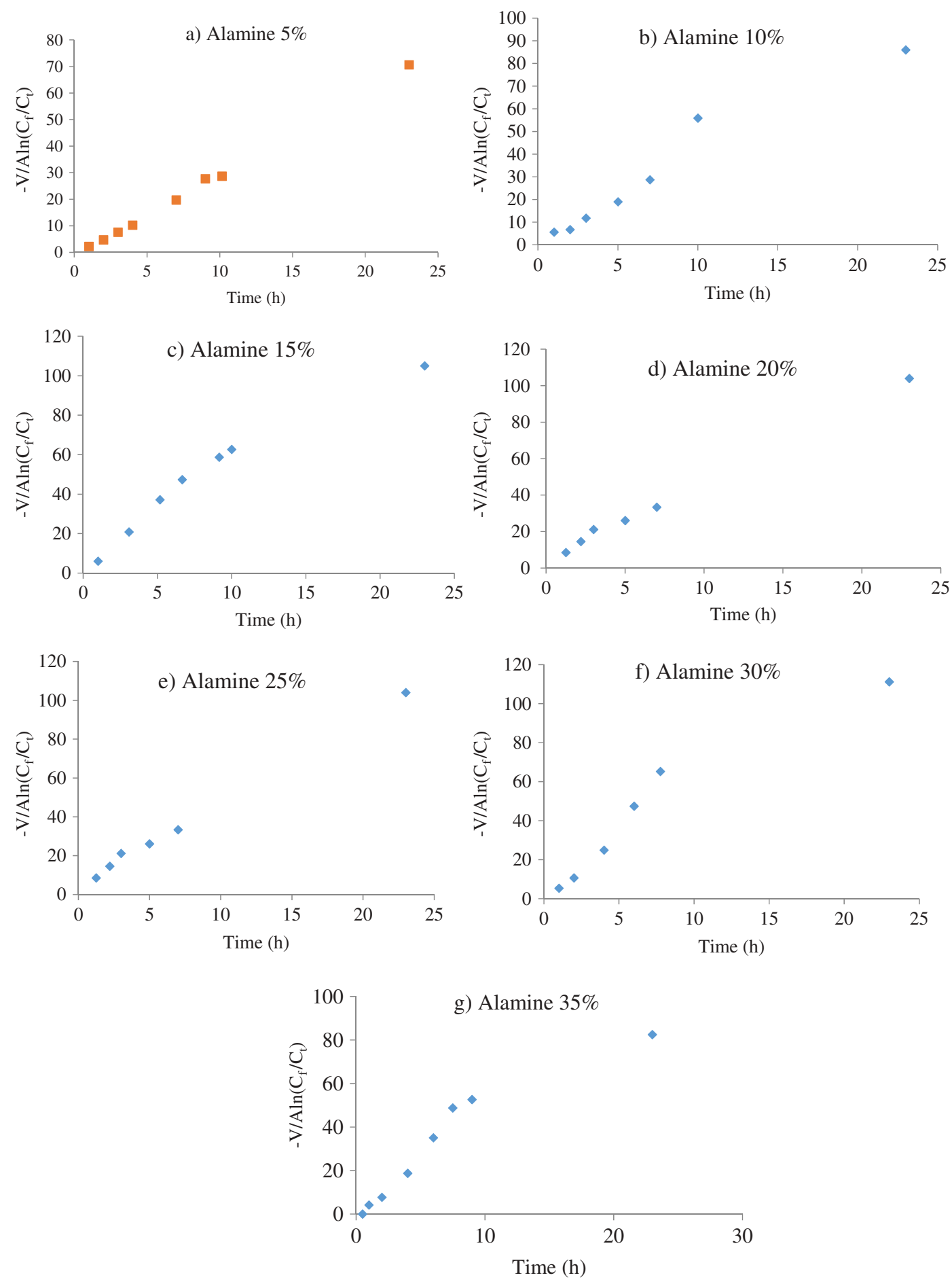

Figure 3. Plots of $\mathrm{V} / \mathrm{A}\left(\ln \left(\mathrm{C}_{\mathrm{f}} / \mathrm{C}_{\mathrm{t}}\right)\right.$ as a function of time at various concentrations of Alamine 336 (a) $5 \% \mathrm{v} / \mathrm{v}$, (b) $10 \% \mathrm{v} / \mathrm{v}$, (c) $15 \% \mathrm{v} / \mathrm{v}$, (d) $20 \% \mathrm{v} / \mathrm{v}$, (e) $25 \% \mathrm{v} / \mathrm{v}$, (f) $30 \% \mathrm{v} / \mathrm{v}$, and (g) $35 \% \mathrm{v} / \mathrm{v}$ (the concentration of $\mathrm{Ge}, \mathrm{Ni}, \mathrm{Cd}$, and Co of $100 \mathrm{mg} / \mathrm{L}$ as well as $\mathrm{Zn}$ of $1000 \mathrm{mg} / \mathrm{L}$, tartaric acid amount equal to two times the germanium mole amount, and concentration of $1 \mathrm{~mol} / \mathrm{L}$ ).

seen in a trend curve plotted in Fig. 4. According to this discussion, the Alamine 336 concentration of $15 \%$ was selected as an optimum concentration of the carrier in further experiments.

The separation factor was calculated by dividing $\mathrm{P}_{\mathrm{Ge}}$ to $\mathrm{P}_{\text {metal }}$ (metal: $\mathrm{Zn}, \mathrm{Cd}, \mathrm{Co}$, or $\mathrm{Ni}$ ) to show the selectivity of various Alamine 336 concentrations. Table 3 shows the separation factors of $\alpha_{\mathrm{Ge} / Z n}, \alpha_{\mathrm{Ge} / \mathrm{Cd}}$, $\alpha_{\mathrm{Ge} / \mathrm{Co}}$, and $\alpha_{\mathrm{Ge} / \mathrm{Ni}}$. Since the concentration of zinc and nickel in the strip phase was below $5 \mathrm{mg} / \mathrm{L}$ and that of the other metals were close to 0 , the calculation of this factor was imprecise because the concentrations were 


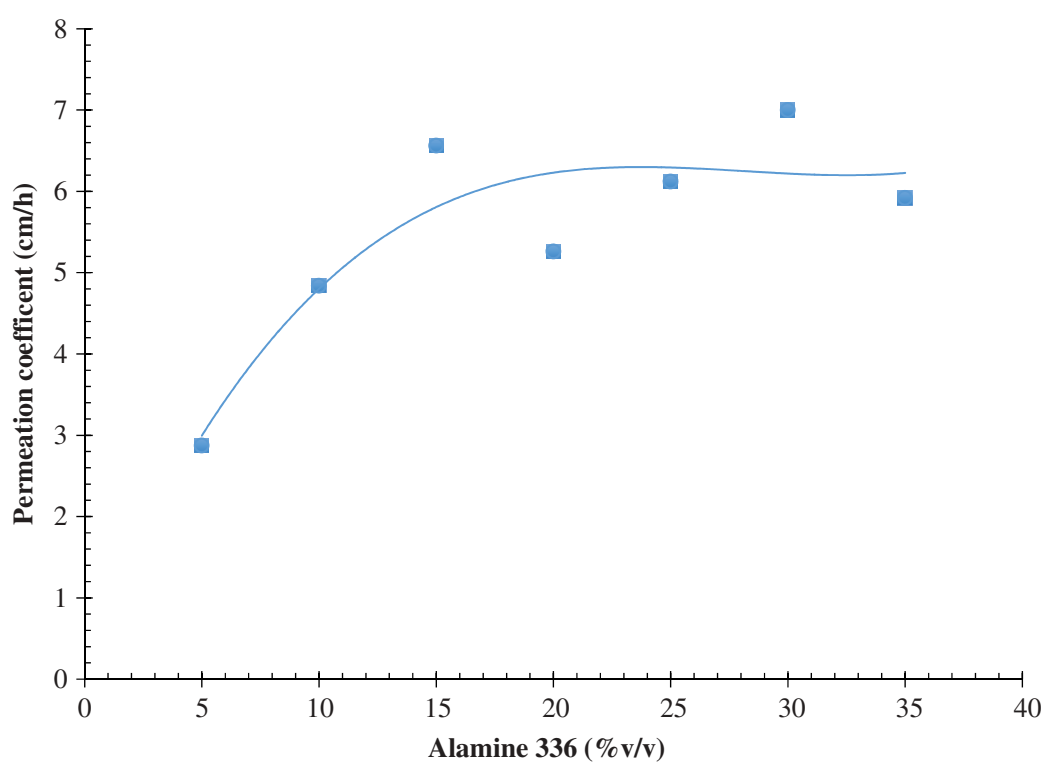

Figure 4. Effect of the carrier (Alamine 336) concentration on the permeation coefficient of germanium (the condition similar to Fig. 3).

Table 3. Separation factor in various concentrations of Alamine 336 (in the same condition mentioned in Fig. 3).

\begin{tabular}{lcccc}
\hline Alamine 336 (\%) & $\mathrm{a}_{\mathrm{Ge} / \mathrm{Zn}}$ & $\mathrm{a}_{\mathrm{Ge} / \mathrm{Cd}}$ & $\mathrm{a}_{\mathrm{Ge} / \mathrm{Co}}$ & $\mathrm{a}_{\mathrm{Ge} / \mathrm{Ni}}$ \\
\hline 5 & 287.00 & 289.90 & $\infty$ & 287.00 \\
10 & 306.15 & 496.25 & $\infty$ & 30.61 \\
15 & 841.02 & 3123.81 & $\infty$ & $\infty$ \\
20 & 406.92 & 556.84 & $\infty$ & $\infty$ \\
25 & 780.82 & $\infty$ & $\infty$ & $\infty$ \\
30 & 2556.52 & $\infty$ & $\infty$ & $\infty$ \\
35 & 3458.82 & $\infty$ & $\infty$ & $\infty$ \\
\hline
\end{tabular}

below detection limit (BDL). As seen in this table, the values of the separation factor for Ge/Co were extreme. These values for $\mathrm{Ge} / \mathrm{Ni}$ reached extremes at higher concentrations of the carrier. Hence, the transport of cobalt and nickel is insignificant. The value of the separation factor for $\mathrm{Ge} / \mathrm{Cd}$ was found to be 289.90 at the Alamine 336 concentration of $5 \%$. This value reached 3123.81 with an enhancement of the Alamine 336 concentration up to $15 \%$, whereas at the concentration of $20 \%$, the value descended followed by reaching extreme values at higher concentrations. Similar increases and decreases were observed for the separation factors of $\mathrm{Ge} / \mathrm{Zn}$. The mentioned irregular increase and decrease in separation factors of germanium and zinc and cadmium are due to the proximity and low values of concentrations resulted from the measurement error of the analytical instrument. Generally, at higher concentrations of Alamine 336, higher separation factors were observed; however, the reduction of the germanium transport through the membrane due to the high viscosity in higher concentrations led to selecting the concentration of $15 \%$ as an optimum condition of the carrier concentration.

\section{Effect of germanium concentration}

In order to find the effect of the germanium concentration on the species transport, it was varied in the range of 25 to $100 \mathrm{mg} / \mathrm{L}$. This range was selected with respect to the germanium concentrations of leach liquors mentioned in the literature. ${ }^{[5,7,9,42]}$ According to LLX experiments, the presence and concentrations of the other heavy metals could not significantly affect the germanium extraction. ${ }^{[34]}$ Therefore, their concentrations were set at a fixed level. Moreover, tartaric acid in the feed phase was held constant at a molar ratio of tartaric acid to $\mathrm{Ge}$ equal to 2 . Figure 5 shows the effect of the germanium concentration in the feed phase on its transport. The curve corresponding to $25 \mathrm{mg} / \mathrm{L}$ shows the slowest transport rate and the maximum transport efficiency reached $90 \%$ after about $23 \mathrm{~h}$. The highest transport rate is related to the $50 \mathrm{mg} / \mathrm{L}$ curve. In this concentration, about $90 \%$ of germanium was transported after $10 \mathrm{~h}$ and the quantitative transport (99\%) took place after $23 \mathrm{~h}$. With an increase in the germanium concentration from 25 to $50 \mathrm{mg} / \mathrm{L}$, the germanium permeation coefficient $(\mathrm{P})$ enhanced from 2.55 to $8.32 \mathrm{~cm} /$ $\mathrm{h}$. This increase is in agreement with the expected tendency shown in Eq. (2). This enhancement took place due to an enhancement of germanium-extractant complexes in the interface of the solution-membrane. With a further increase in the concentration up to $100 \mathrm{mg} / \mathrm{L}$, 


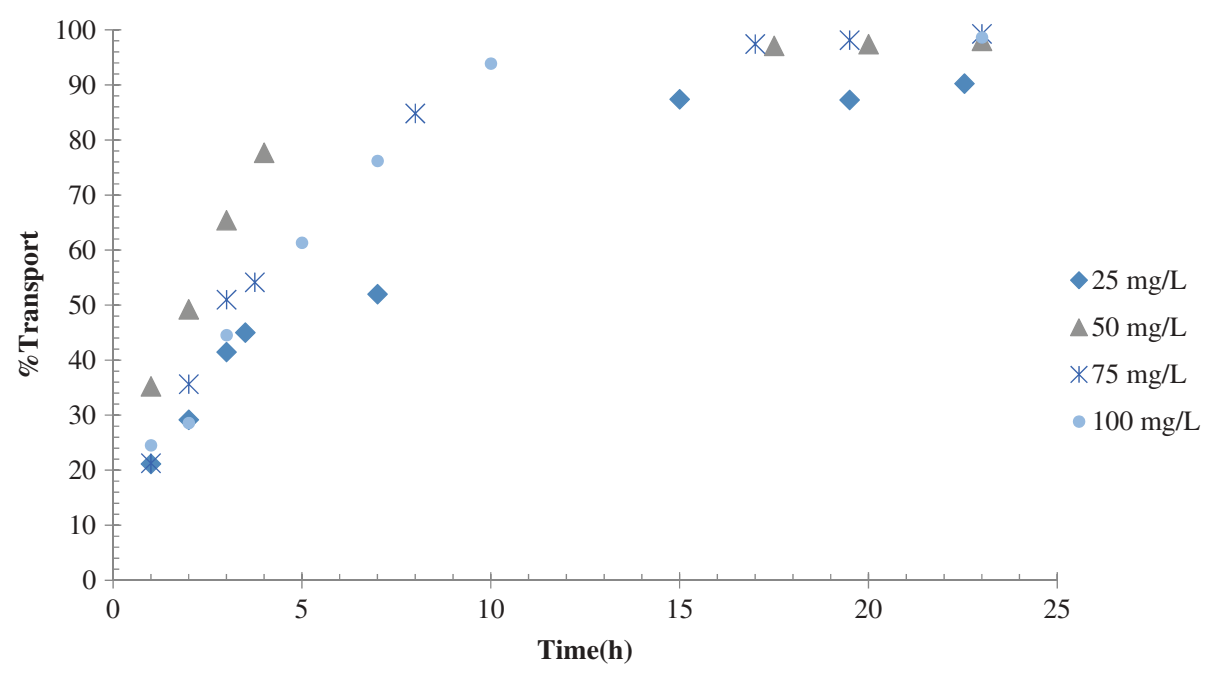

Figure 5. Effect of the germanium concentration on the germanium transport efficiency (the concentration of $\mathrm{Ni}$, $\mathrm{Cd}$, and $\mathrm{Co}$ equal to $100 \mathrm{mg} / \mathrm{L}, \mathrm{Zn}$ of $1,000 \mathrm{mg} / \mathrm{L}$, tartaric acid amount equal to two times the germanium mole amount, Alamine 336 concentration of $15 \% \mathrm{v} / \mathrm{v}$, and $\mathrm{HCl}$ concentration of $1 \mathrm{~mol} / \mathrm{L})$.

the transport rate descended. The transport curves corresponding to germanium concentrations of 75 and $100 \mathrm{mg} / \mathrm{L}$ are close together and have the same trend. The quantitative transport (99\%) in these concentrations was obtained after about $23 \mathrm{~h}$. At the germanium concentration of $100 \mathrm{mg} / \mathrm{L}$, the permeation coefficient $(\mathrm{P})$ descended to $6.56 \mathrm{~cm} / \mathrm{h}$. The reason for this decrease is possibly due to the low effective membrane area resulted from the saturation of the membrane. ${ }^{[43]}$ This means that membrane pores are saturated with germanium species and a layer is formed on the interface of the feedmembrane, resulting in an increase of the retention time of species in the pores.

\section{Effect of different tartaric acid salt $\left(\mathrm{C}_{4} \mathrm{H}_{6} \mathrm{O}_{6}\right)$}

With respect to the neutral nature of dissolved germanium in the water medium and anionic exchange behavior of the extractant (Alamine 336), the conversion of germanium to an anionic complex is essential for the germanium transport by Alamine 336. Carboxylates and some organic base materials are some options for this conversion. Since organic reagents, such as catechol have aromatic nature and are dangerous for the environment, the environment-friendly alternatives such as carboxylates (citric acid, oleic acid, oxalic acid, tartaric acid, etc.) were preferred to be used in this study. According to the liquid-liquid extraction results reported elsewhere ${ }^{[29,30,34]}$, tartaric acid has an efficient effect on the formation of germanium anionic complexes. Therefore, this acid was used in the experiments. The reaction between germanium neutral species and tartrate anions produces anionic species of
$\mathrm{Ge}(\mathrm{OH})_{2}\left(\mathrm{C}_{4} \mathrm{H}_{4} \mathrm{O}_{6}\right)^{2-}$. This anionic complex can be transported by an amine carrier in the SLM process.

To find the effect of tartaric acid on the facilitated transport of germanium, its concentrations varied in the range of 0.2 to 2 times the Ge concentration in the feed phase (i.e. equal to 0.276 to $2.76 \mathrm{mmol} / \mathrm{L}$ ). SLM transport experiments were carried out keeping all parameters constant. The transport efficiency of germanium through SLM as a function of time for various tartaric acid concentrations has been shown in Fig. 6a. It is obvious that with an increase in tartaric acid concentrations up to 2 molar ratios $(2.76 \mathrm{mmol} / \mathrm{L})$, the germanium transport significantly increases. The initial enhancement in the transport with enhancing the tartaric acid concentration is due to an increase in the germanium tartrate complex formation. As a result, the quantitative transport of germanium (100\%) obtained during $10 \mathrm{~h}$ at the tartaric acid concentration of 2 molar ratios, showing the highest transport rate at this concentration. As seen in the figure, the maximum transport efficiency corresponding to the tartaric acid to germanium molar ratios of 1.5, 1, 0.5, and 0.2 were found to be $95 \%, 82 \%, 49 \%$, and $24 \%$ after about $23 \mathrm{~h}$. These values show that the transport rate significantly descended with decreasing the tartaric acid concentration. The reason for this decrease is that the number of tartrate molecules that should react with germanium species is not sufficient.

The permeation coefficient $\left(\mathrm{P}_{\mathrm{Ge}}\right)$ enhanced from 0.76 up to $6.56 \mathrm{~cm} / \mathrm{h}$ when tartaric acid concentration increased from 0.2 up to 2 molar ratios. A further increase of $\mathrm{C}_{4} \mathrm{H}_{6} \mathrm{O}_{6}$ up to 3 molar ratios has no effect on the germanium permeation through the liquid 

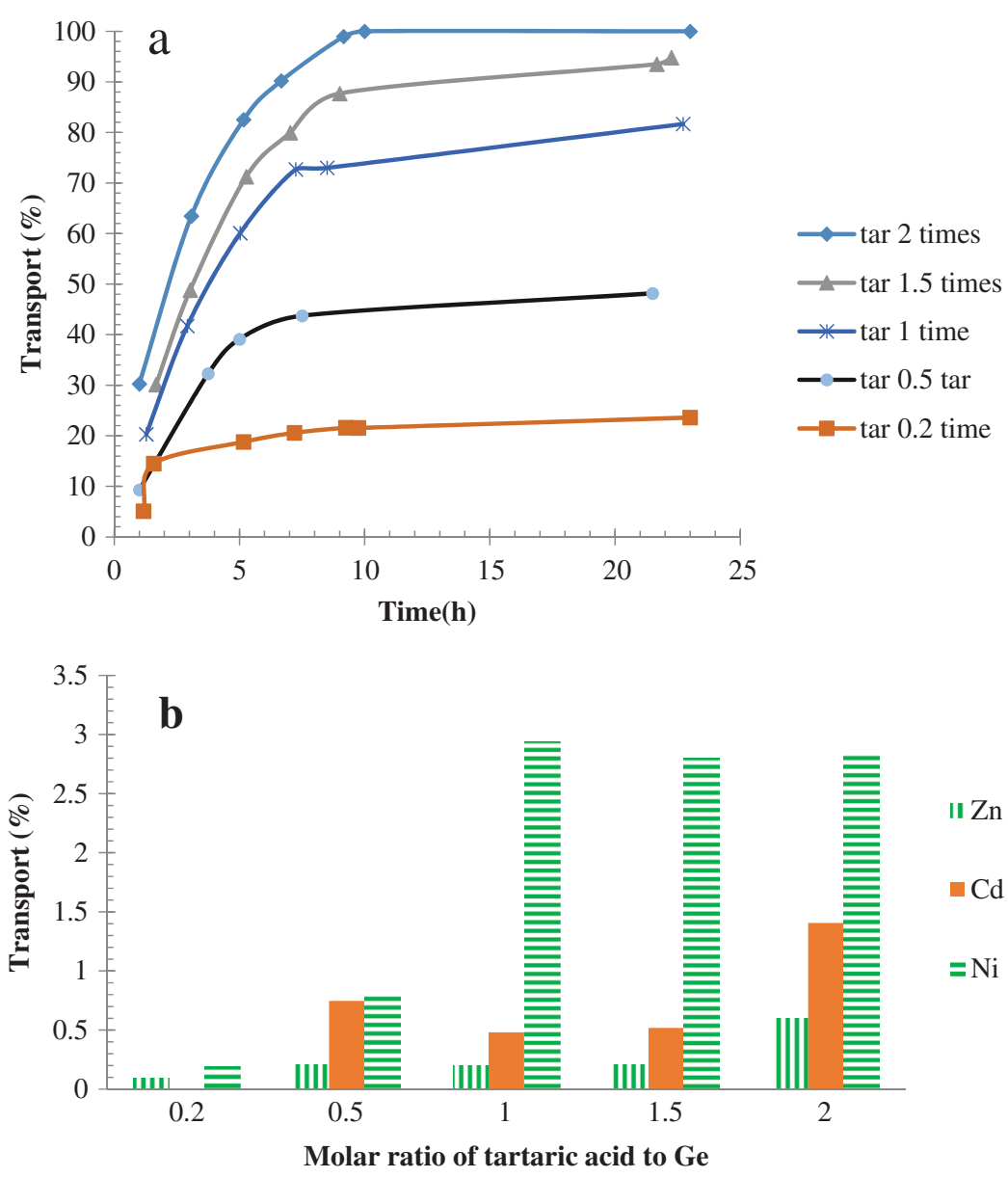

Figure 6. Effect of the tartaric acid amount on the transport efficiency of (a) germanium and (b) impurities (the concentration of Ge, $\mathrm{Ni}, \mathrm{Cd}$, and Co of $100 \mathrm{mg} / \mathrm{L}$ as well as $\mathrm{Zn}$ of $1,000 \mathrm{mg} / \mathrm{L}$, Alamine 336 concentration of $15 \% \mathrm{v} / \mathrm{v}$ and $\mathrm{HCl}$ concentration of $1 \mathrm{~mol} / \mathrm{L}$ ).

membrane. With increasing tartaric acid, its cotransport enhances due to the extraction of anionic species of tartare by Alamine 336. With an increase of the tartare co-transport, the free Alamine 336 concentration in the membrane phase decreases, resulting in decreasing the transport efficiency. This factor is the reason for the insignificant effect of tartaric acid concentration on the germanium permeation at concentrations higher than the tartaric acid to germanium molar ratio of 2 .

Moreover, Fig. $6 \mathrm{~b}$ illustrates the transport efficiency of impurities vs. time through the SLM for various concentrations of tartaric acid. As seen in this figure, the transport efficiency of zinc, cadmium, and nickel increased with an enhancement of the tartaric acid up to $0.59 \%, 1,40 \%$, and $2.83 \%$, respectively. It is noted that the cobalt transport was not observed during the experiments. Nevertheless, since concentrations of impurities transported were below $5 \mathrm{mg} / \mathrm{L}$, the values were below detection limit (BDL). For this reason, the transport efficiencies calculated for these impurities were not imprecise. The low permeation of impurities is due to the lack of anionic species formation of these heavy metals with tartrate anions. ${ }^{[34]}$ This low permeation is because tartrates of these elements have low stability constants in the condition of this study. According to the literature, the logarithm of stability constants of zinc-, nickel-, cobalt-, and cadmiumtartrate has been calculated to be $2.39^{[44]}, 2.32^{[44]}$, $2.26^{[44]}$, and $2.27^{[45]}$, respectively.

\section{Effect of strip solution concentration on the permeation}

Strippant in the receiving phase is essential to transport germanium from the feed phase to strip phase through the liquid membrane. ${ }^{[46]}$ If the stripping agent and its concentration are not proper, desired complexes are not appropriately transported through SLM; therefore, species are associated with the membrane phase followed by saturating. ${ }^{[46]}$ In this study, $\mathrm{HCl}$ was selected as a strip reagent. The effect of $\mathrm{HCl}$ in the strip solution on the transport efficiency was investigated by varying its 
concentration in the range of 0.25 to $2 \mathrm{~mol} / \mathrm{L}$. This range was selected according to the liquid-liquid extraction conducted before and the results were reported elsewhere. ${ }^{[34]}$ The effect of $\mathrm{HCl}$ concentration on the transport of germanium is illustrated in Fig. 7a. As seen in the figure, with an enhancement of $\mathrm{HCl}$ concentration, the transport efficiency of germanium enhanced. This transport enhancement up to the $\mathrm{HCl}$ concentration of $0.5 \mathrm{~mol} / \mathrm{L}$ is due to the increase in the de-complexation of species taking place at the interface of the receiving and membrane phases shown as Eq. (3). ${ }^{[34]}$ This resulted in hastening the germanium transport through SLM.

$$
\begin{aligned}
& {\left[\left(\mathrm{R}_{3} \mathrm{NH}\right)_{2} \mathrm{Ge}(\mathrm{OH})_{2}(\mathrm{~T})\right]_{(\mathrm{org})}+2 \mathrm{Cl}_{(\mathrm{aq})}+\mathrm{H}^{+}} \\
& \quad=2\left(\mathrm{R}_{3} \mathrm{NHCl}\right)_{(\text {org })}+\mathrm{Ge}(\mathrm{OH})_{2}(\mathrm{HT})^{-}{ }_{(a q)}
\end{aligned}
$$

However, there was an insignificant difference between the curves belonging to $\mathrm{HCl}$ concentrations higher than $0.5 \mathrm{~mol} / \mathrm{L}$. This means that germanium is readily stripped at lower acidic concentrations. On the other hand, at the $\mathrm{HCl}$ concentration of $2 \mathrm{~mol} / \mathrm{L}$, the transport has been descended. This reduction is probably due to the addition of $\mathrm{Cl}^{-}$ions in the strip solution resulted in an inverse $\mathrm{HCl}$ transport through the pores of the membrane to the feed phase. At a high concentration of $\mathrm{HCl}$, Alamine 336 molecules would increasingly combine with $\mathrm{Cl}^{-}$ions at the interface of the membrane and the strip phase. Thus, the number of carrier molecules reacting with germanium tartrate molecules in the feed phasemembrane interface descends, resulting in decreasing the transport. Similar results published by Zaheri et al. ${ }^{[47]}$ have been shown for the europium transport across an SLM system using Cyanex 272 with a strip solution containing $\mathrm{HNO}_{3}$. Furthermore,
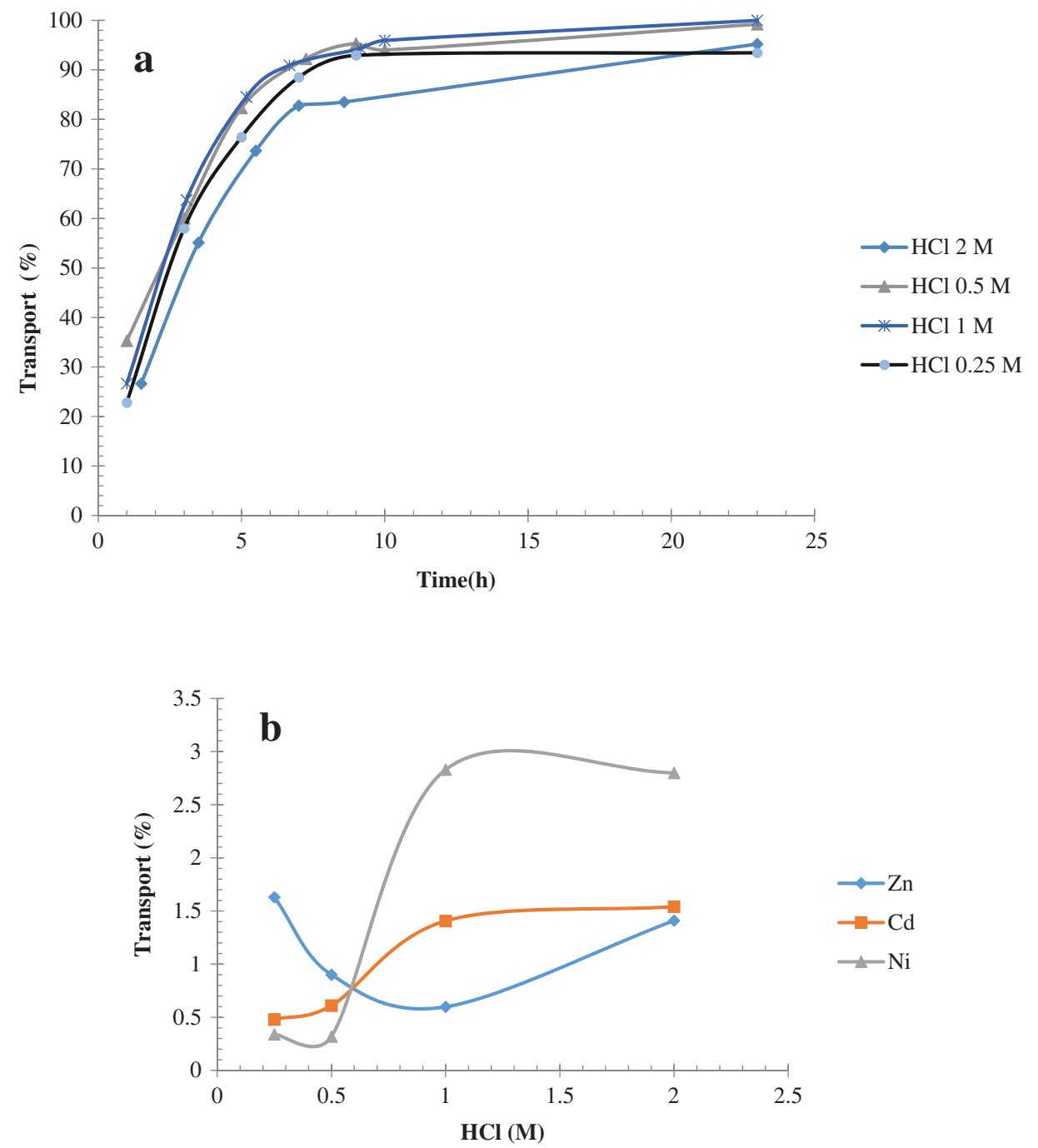

Figure 7. Effect of the $\mathrm{HCl}$ concentration on the transport efficiency of (a) germanium and (b) impurities (the concentration of Ni, Cd, and $\mathrm{Co}$ of $100 \mathrm{mg} / \mathrm{L}$ as well as $\mathrm{Zn}$ of $1,000 \mathrm{mg} / \mathrm{L}$, tartaric acid amount of two times the germanium mole amount, and Alamine 336 concentration of $15 \% \mathrm{v} / \mathrm{v})$. 
it has been reported that the SLM stability descends at higher concentrations of acids in a strip phase due to the reduction of the interfacial tension between the membrane and the strip solution. ${ }^{[48]}$ In the strip solution concentration above $0.5 \mathrm{~mol} / \mathrm{L} \mathrm{HCl}$, decomposition of transported germanium species is induced by the interfacial reactions and takes place promptly. Consequently, the subsequent diffusion of species into the strip solution does not depend on the acid concentration at the concentration above $0.5 \mathrm{~mol} / \mathrm{L}^{\left[{ }^{[9]}\right]}$

Figure $7 \mathrm{~b}$ reveals the effect of $\mathrm{HCl}$ in the strip solution on the transport efficiency of other metals existing in the feed solution. As seen in this figure, the transport efficiency of nickel and cadmium increased with increasing the $\mathrm{HCl}$ concentration, whereas the transport efficiency of zinc initially descended, and then increased with the further enhancement of $\mathrm{HCl}$. Similar discussions mentioned for germanium can be considered for the mentioned transport enhancement. According to results, the maximum transport efficiency of $\mathrm{Ni}, \mathrm{Cd}$, and $\mathrm{Zn}$ were obtained to be $2.8,1.51$, and $1.41 \%$ at $2 \mathrm{~mol} / \mathrm{L}$ of $\mathrm{HCl}$, respectively. Furthermore, since the cobalt transport across the membrane was close to $0 \mathrm{mg} / \mathrm{L}$, the corresponding curve was not shown. Therefore, the transport of these metals to the strip phase is not noteworthy in comparison to the germanium transport. As mentioned before, since concentrations of impurities transported were below $5 \mathrm{mg} / \mathrm{L}$, the values were below detection limit (BDL). For this reason, the transport efficiency calculated for these impurities was not imprecise.

\section{Effect of membrane type on the permeation}

To identify the effect of the membrane type on the germanium transport, a polyvinylidene difluoride (PVDF) hydrophobic membrane was used. In this regard, two PVDF membranes with pore sizes of 0.22 and $0.45 \mu \mathrm{m}$ were used. It is noticed that the thickness of these types of membranes was $125 \mu \mathrm{m}$, whereas that for the PTFE membrane used in this study was $50 \mu \mathrm{m}$. The experiments were conducted at a feed solution containing $100 \mathrm{mg} / \mathrm{L}$ of $\mathrm{Ge}, \mathrm{Ni}, \mathrm{Cd}$, Co and 1,000 mg/L of $\mathrm{Zn}$. Furthermore, the amount of tartaric acid added was kept at two times the germanium mole amount in the feed phase. Furthermore, the $\mathrm{HCl}$ concentration was set at $1 \mathrm{~mol} / \mathrm{L}$ in the strip phase. The results of the mentioned experiments were illustrated in Fig. 8 and compared to the PTFE result.

As seen in this figure, the transport efficiency (\%T) and the transport rate of germanium across the PTFE membrane at the same experimental condition is more than that of the PVDF membranes. The large distance between the transport curves of PTFE and PVDF membranes shows this. According to the results, $96 \%$ of germanium transported through the PTFE membrane after $10 \mathrm{~h}$, whereas about $75 \%$ of germanium transported across the PVDF membranes during the mentioned time. Furthermore, this figure and the calculation of the permeation coefficients showed that permeation of germanium across PTFE membrane $(\mathrm{P}=6.56 \mathrm{~cm} / \mathrm{h})$ is higher than $\mathrm{PVDF}$ membranes $\left(\mathrm{P}_{0.25}=3.86\right.$ and $\left.\mathrm{P}_{0.45}=4.58\right)$. Since the thickness of the PTFE membrane used in this study is lower than that of the PVDF membranes, it can be expressed that

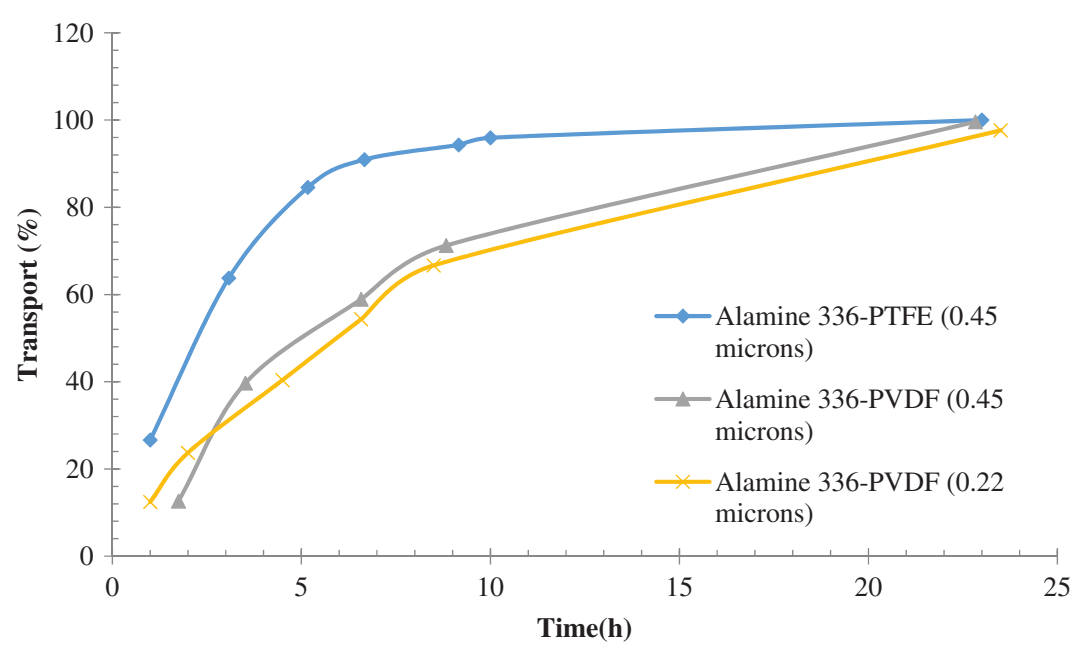

Figure 8. Transport efficiency of germanium through PTFE and PVDF membranes (the concentration of Ni, Cd, and Co of $100 \mathrm{mg} / \mathrm{L}$ as well as $\mathrm{Zn}$ of $1,000 \mathrm{mg} / \mathrm{L}$, tartaric acid amount two times the germanium mole amount, Alamine 336 concentration of $15 \% \mathrm{v} / \mathrm{v}$ and $\mathrm{HCl}$ concentration of $1 \mathrm{~mol} / \mathrm{L})$. 
the lower permeation in the PVDF membranes is probably because of the long diffusion path length. According to Schofield's model, the membranes with a higher thickness have a long distance for transporting diffused species through the membrane, leading to a decrease in the flux, the transport efficiency, and the permeability coefficient. ${ }^{[50]}$ In addition to the abovementioned reasons, low tortuosity and high porosity of PTFE membranes make them more efficient than PVDF membranes. ${ }^{[50]}$ Eq. (4) shows the relationship of diffusion $(D)$, distribution coefficient $\left(D_{G e}\right)$, tortuosity $(\tau)$, and porosity $(\rho)$ :

$$
D=D_{G e}\left(\frac{\rho}{\tau}\right)
$$

This equation shows that high porosity and low tortuosity resulted in high diffusion through the membrane. The porosity of the PTFE and PVDF membranes used in this study was $85 \%$ and $70 \%$, respectively. Furthermore, the tortuosity values of PTFE and PVDF membranes were reported to be $1.1^{[51]}$ and $2.12^{[52,53]}$, respectively.

Furthermore, results showed that the germanium permeation across the $0.45 \mu \mathrm{m}$ PVDF membrane $\left(\mathrm{P}_{0.45}=4.58\right)$ is a bit more than the $0.22 \mu \mathrm{m}$ membrane $\left(\mathrm{P}_{0.25}=3.86\right)$. The vicinity of the transport curves of PVDF membranes confirms this. Since the role of a supported liquid membrane is the physical separation of the feed and strip phases, an increase in the pore size enhances the transport of ion species. With respect to the Stokes-Einstein law, the diffusion coefficient of desired species inversely depends on the radius of the diffusing ions. ${ }^{[54]}$ Hence, the resistance of the species transport is higher across membranes with a lower pore size, resulting in a higher transport rate for membranes with larger pore sizes.

\section{Transport of $\mathrm{Ge}(\mathrm{IV})$ through HFSLM}

After obtaining the optimum condition of the germanium transport through the FSSLM, a transport experiment was conducted using an HFSLM system in the following condition: the initial germanium concentration of about $88 \mathrm{mg} / \mathrm{L}$, tartaric acid equal to two times the germanium mole amount, Alamine 336 concentration of $5 \% \mathrm{v} / \mathrm{v}$, and $\mathrm{HCl}$ concentration of $1 \mathrm{~mol} / \mathrm{L}$ in the strip solution. The $\mathrm{pH}$ of the initial feed solution was set at 2.30 that reached 2.32 after the experiment. Since the transport of $\mathrm{Ni}, \mathrm{Cd}, \mathrm{Co}$, and $\mathrm{Zn}$ was approximately zero, the corresponding results are not shown here. The result of the HFSLM experiment was plotted in Fig. 9. The germanium concentration in the feed phase reduced by prolonging the time until $180 \mathrm{~min}$, whereas the concentration in the strip phase gradually increased up to a steady state level. The maximum concentration of germanium in the strip phase reached $350 \mathrm{mg} / \mathrm{L}$, which is approximately 4 times the initial concentration. Therefore, a concentrated solution of germanium was obtained which can be proceeded for further metallurgical processes. As seen in Fig. 9, in initial times, the transport rate of germanium in the feed phase is faster than that in the strip phase. Similar results have been observed in several studies. ${ }^{[15,55,56]}$ This difference is due to a part of germanium remaining in the membrane phase, which slowly enters the strip phase (see the cross-shaped curve in Fig. 9). This probably occurs

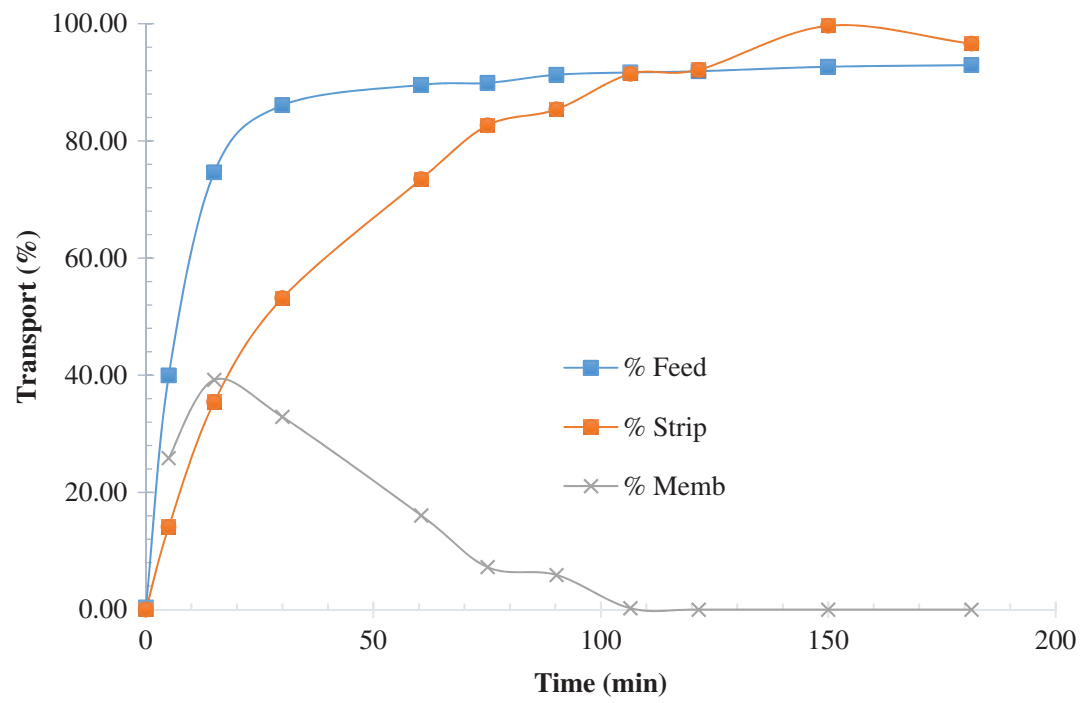

Figure 9. Transport of germanium through the HFSLM system during $180 \mathrm{~min}$ (Operational condition: feed and strip flow rates of $28 \mathrm{~L} / \mathrm{h}$ and $23 \mathrm{~L} / \mathrm{h}$, respectively; chemical condition: the concentration of $\mathrm{Ge} 88 \mathrm{mg} / \mathrm{L}$, tartaric acid amount of two times the germanium mole amount, Alamine 336 concentration of $5 \% \mathrm{v} / \mathrm{v}$ and $\mathrm{HCl}$ concentration of $1 \mathrm{~mol} / \mathrm{L}$ ). 
due to the existence of several residences against the germanium diffusion from the feed bulk to the strip bulk. Furthermore, different reaction rates of the extraction and stripping can justify the slow transport of germanium to the strip phase. ${ }^{[15]}$ As shown in the cross-shaped curve in Fig. 9, the remaining germanium in the membrane side descends to zero after reaching the equilibrium and steady-state condition. As a result, an appropriate transport could be achieved after $150 \mathrm{~min}$. Consequently, it was seen that the HFSLM system could efficiently separate and enrich germanium from various industrial effluents such as coal gasification fly ash leach liquors. In order to compare the extraction efficiency of germanium in an LLX system with the germanium transport across the HFSLM, an LLX experiment was carried out in the same condition mentioned for the HFSLM system. The results showed that the germanium extraction efficiency in the LLX system reached $90 \%$ after $30 \mathrm{~min}$. During this duration, the transport efficiency of germanium was found to be $86.08 \%$ across HFSLM while this value reached $24.8 \%$ for an FSSLM system containing 5\%v/v Alamine 336. These values indicated the fact that the germanium extraction in the LLX system is comparable to the HFSLM system.

\section{Conclusion}

The present research has investigated the separation of germanium species from neutral solutions such as leach liquors obtained from coal gasification fly ash leaching processes through an FSSLM using Alamine 336 as a carrier. The separation of germanium from zinc, nickel, cobalt, and cadmium was carried out in various conditions. The results showed that the appropriate separation of germanium from heavy metals can be achieved with Alamine 336 concentrations higher than $10 \% \mathrm{v} / \mathrm{v}$. The essential role of tartaric acid as a complexant is to convert germanium to anionic species. In the absence of tartaric acid, the transport of germanium was not possible. Various concentrations of $\mathrm{HCl}$ in the strip phase were examined and the results showed that $\mathrm{HCl}$ concentrations above $0.5 \mathrm{~mol} / \mathrm{L}$ are proper to create an appropriate gradient. With respect to the FSSLM experimental optimum condition, a hollow fiber supported liquid membrane system was run and the results showed the faster transport of germanium in this system. In addition, these results indicated the fact that the germanium extraction in the LLX system is comparable to the HFSLM system. This system can be used in the scaled-up system for the industrial enrichment and purification of germanium solutions.

\section{Acknowledgments}

This research was done in the laboratory of the Department of Chemical Engineering, Universitat Politècnica de Catalunya (Barcelona-Tec), Vilanova i la Geltrú Campus, Spain. The authors thank Dr. Maria Teresa Coll for her assistance and scientific consultation.

\section{ORCID}

Mehdi Irannajad (D) http://orcid.org/0000-0002-5469-084X

\section{References}

[1] Licht, C.; Peiró, L.T.; Villalba, G. (2015) Global substance flow analysis of gallium, germanium, and indium: quantification of extraction, uses, and dissipative losses within their anthropogenic cycles. Journal of Industrial Ecology, 19 (5): 890-903. doi:10.1111/ jiec. 12287

[2] Arroyo, F.; Font, O.; Fernández-Pereira, C.; Querol, X.; Chimenos, J.; Zeegers, H. (2009) Germanium and gallium extraction from gasification fly ash: optimisation for up-scaling a recovery process. In World of Coal Ash Conference. Avaible at: http://www.flyash.info.

[3] Liu, J.; Chen, J.; Huang, L. (2015) Heavy metal removal from MSS fly ash by thermal and chlorination treatments. Scientific Reports, 5: 17270. doi:10.1038/ srep 17270

[4] Hu, Y.; Zhang, P.; Li, J.; Chen, D. (2015) Stabilization and separation of heavy metals in incineration fly ash during the hydrothermal treatment process. Journal of Hazardous Materials, 299: 149-157. doi:10.1016/j. jhazmat.2015.06.002

[5] Arroyo, F.; Fernández-Pereira, C. (2008) Hydrometallurgical recovery of germanium from coal gasification fly ash. Solvent extraction method. Industrial \& Engineering Chemistry Research, 47 (9): 3186-3191. doi:10.1021/ie7016948

[6] Zhang, L.; Xu, Z. (2016) An environmentally-friendly vacuum reduction metallurgical process to recover germanium from coal fly ash. Journal of Hazardous Materials, $\quad 312$ : 28-36. doi:10.1016/j. jhazmat.2016.03.025

[7] Arroyo, F.; Font, O.; Fernández-Pereira, C.; Querol, X.; Juan, R.; Ruiz, C.; Coca, P. (2009) Germanium recovery from gasification fly ash: evaluation of end-products obtained by precipitation methods. Journal of Hazardous Materials, 167 (1): 582-588. doi:10.1016/j. jhazmat.2009.01.021

[8] Zhang, L.; Xu, Z. (2017) Application of vacuum reduction and chlorinated distillation to enrich and prepare pure germanium from coal fly ash. Journal of Hazardous Materials, 321: 18-27. doi:10.1016/j. jhazmat.2016.08.070

[9] Torralvo, F.A.; Fernández-Pereira, C. (2011) Recovery of germanium from real fly ash leachates by ion-exchange extraction. Minerals Engineering, 24 (1): 35-41. doi:10.1016/j.mineng.2010.09.004

[10] Li, Z.; Chen, M.; Zhang, Q.; Liu, X.; Saito, F. (2017) Mechanochemical processing of molybdenum and 
vanadium sulfides for metal recovery from spent catalysts wastes. Waste Management, 60: 734-738. doi:10.1016/j.wasman.2016.06.035

[11] Iannicelli-Zubiani, E.M.; Giani, M.I.; Recanati, F.; Dotelli, G.; Puricelli, S.; Cristiani, C. (2017) Environmental impacts of a hydrometallurgical process for electronic waste treatment: A life cycle assessment case study. Journal of Cleaner Production, 140 (Part 3): 1204-1216. doi:10.1016/j.jclepro.2016.10.040

[12] Rounaghi, G.; Mohammadzadeh Kakhki, R.; Eshghi, H. (2017) Efficient transport of lead(II) cations in natural water using a liquid membrane system with dicyclohexano-18-crown-6 as carrier. Arabian Journal of Chemistry, 10: S339-S346. doi:10.1016/j. arabjc.2012.09.004

[13] Swain, B.; Jeong, J.; Lee, J.-C.; Lee, G.-H. (2007) Extraction of $\mathrm{Co}(\mathrm{II})$ by supported liquid membrane and solvent extraction using Cyanex 272 as an extractant: A comparison study. Journal of Membrane Science, 288 (1-2): 139-148. doi:10.1016/j.memsci.2006.11.012

[14] Swain, B.; Mishra, C.; Jeong, J.; Lee, J.-C.; Hong, H.S.; Pandey, B.D. (2015) Separation of Co(II) and Li(I) with Cyanex 272 using hollow fiber supported liquid membrane: A comparison with flat sheet supported liquid membrane and dispersive solvent extraction process. Chemical Engineering Journal, 271: 61-70. doi:10.1016/ j.cej.2015.02.040

[15] Wannachod, T.; Leepipatpiboon, N.; Pancharoen, U.; Nootong, K. (2014) Separation and mass transport of $\mathrm{Nd}$ (III) from mixed rare earths via hollow fiber supported liquid membrane: experiment and modeling. Chemical Engineering Journal, 248: 158-167. doi:10.1016/j.cej.2014.03.024

[16] Suwatthikul, A.; Laisua, N.; Kittisupakorn, P. (2016) Improvement of palladium ions recovery via Hollow fiber supported liquid membrane with model predictive control. In 2016 UKACC 11th International Conference on Control (CONTROL); Belfast, UK; pp 1-6.

[17] Pei, L.; Wang, L.; Yu, G. (2012) Study on a novel flat renewal supported liquid membrane with D2EHPA and hydrogen nitrate for neodymium extraction. Journal of Rare Earths, 30 (1): 63-68. doi:10.1016/ S1002-0721(10)60640-0

[18] Willersinn, S.; Bart, H.-J. (2016) Kinetics of Ge(IV) extraction using a microstructured membrane contactor. International Journal of Chemical Kinetics, 48 (10): 609-621. doi:10.1002/kin.2016.48.issue-10

[19] Nusen, S.; Zhu, Z.; Chairuangsri, T.; Cheng, C.Y. (2015) Recovery of germanium from synthetic leach solution of zinc refinery residues by synergistic solvent extraction using LIX 63 and Ionquest 801 . Hydrometallurgy, 151: 122-132. doi:10.1016/j. hydromet.2014.11.016

[20] Gupta, B.; Mudhar, N. (2006) Extraction and separation of germanium using Cyanex 301/Cyanex 923. Its recovery from transistor waste. Separation Science and Technology, 41 (3): 549-572. doi:10.1080/ 01496390500525021

[21] Xiong, J.; Liang, J.; Fan, L.; Xu, K.; Huang, Y. (2012) 2012 international conference on future electrical power and energy systemstudy on extracting of germanium with trioctylamine. Energy Procedia, 17: 1965-1973.

[22] Takemura, H.; Morisada, S.; Ohto, K.; Kawakita, H.; Matsuo, Y.; Fukuda, D. (2013) Germanium recovery by catechol complexation and subsequent flow through membrane and bead-packed bed column. Journal of Chemical Technology and Biotechnology, 88 (8): 1468-1472. doi:10.1002/jctb.2013.88.issue-8

[23] Kuroiwa, K.; Ohura, S.-I.; Morisada, S.; Ohto, K.; Kawakita, H.; Matsuo, Y.; Fukuda, D. (2014) Recovery of germanium from waste solar panels using ion-exchange membrane and solvent extraction. Minerals Engineering, 55: 181-185. doi:10.1016/j. mineng.2013.10.002

[24] Ozawa, I.; Saito, K.; Sugita, K.; Sato, K.; Akiba, M.; Sugo, T. (2000) High-speed recovery of germanium in a convection-aided mode using functional porous hollow-fiber membranes. Journal of Chromatography. A, 888 (1): 43-49.

[25] Soylak, M.; Yigit, S. (2015) Preconcentration-separation of germanium at ultra trace levels on polysulfone membrane filter and its determination by spectrophotometry. Journal of Industrial and Engineering Chemistry, 24: 322-325. doi:10.1016/j.jiec.2014.10.003

[26] Tutkun, O.; Demircan, N.; Kumbasar, R.A. (1999) Extraction of germanium from acidic leach solutions by liquid membrane technique. Clean Technologies and Environmental Policy, 1 (2): 148-153. doi:10.1007/ s100980050019

[27] Taihong, S.; Xiangde, W.; Yinghua, W.; Xiujuan, Z. (1999) Recovery of Ga and Ge from zinc hydrometallurgy system by synchronous transport in emulsion liquid membrane process $(\square)[\mathrm{J}]$. Membrane Science \& Technology, 4: 006.

[28] Liu, F.; Yang, Y.; Lu, Y.; Shang, K.; Lu, W.; Zhao, X. (2010) Extraction of germanium by the AOT Microemulsion with $\mathrm{N} 235$ System. Industrial \& Engineering Chemistry Research, 49 (20): 10005-10008. doi:10.1021/ie100963t

[29] Kamran Haghighi, H.; Irannajad, M.; Moradkhani, D. (2018) Permeation and modeling studies on Ge(IV) facilitated transport using trioctylamine through supported liquid membrane. The Korean Journal of Chemical Engineering, 35 (1): 53-60. doi:10.1007/ s11814-017-0265-0

[30] Kamran Haghighi, H.; Irannajad, M.; Fortuny, A.; Sastre, A.M. (2018) Mathematical modeling for facilitated transport of $\mathrm{Ge}(\mathrm{IV})$ through supported liquid membrane containing Alamine 336. Chemical Papers, 72 (4): 955-970. doi:10.1007/s11696-017-0332-3

[31] Kamran Haghighi, H.; Irannajad, M.; Moradkhani, D. (2018) Facilitated transport of germanium from acidic medium through supported liquid membrane using Cyanex 301 as mobile carrier. Physicochemical Problems of Mineral Processing, Article in Press.

[32] Friess, K.;. (2015) Alamine 336 In: Drioli, E.; Giorno, L. (editors) Encyclopedia of Membranes, 41; Springer: Berlin, Heidelberg.

[33] Trinh, T.T.; Rozanska, X.; Delbecq, F.; Tuel, A.; Sautet, P. (2016) The mechanism of the initial step of germanosilicate formation in solution: a first-principles molecular dynamics study. Physical Chemistry 
Chemical Physics, 18 (21): 14419-14425. doi:10.1039/ c6cp01223j

[34] Kamran Haghighi, H.; Irannajad, M.; Fortuny, A.; Sastre, A.M. (2018) Recovery of germanium from leach solutions of fly ash using solvent extraction with various extractants. Hydrometallurgy, 175: 164-169. doi:10.1016/j.hydromet.2017.11.006

[35] Martsinko, E.E.; Seifullina, I.I.; Minacheva, L.K.; Pesaroglo, A.G.; Sergienko, V.S. (2008) Synthesis, properties, and molecular and crystal structure of diantipyrylmethanium $\quad \operatorname{Bis}(\mu$-tartrato) dihydroxydigermanate(IV) tetrahydrate (HDAm)2 [Ge2( $\mu-\mathrm{L}) 2(\mathrm{OH}) 2]$ • 4H2O. Russian Journal of Inorganic Chemistry, 53 (11): 1694-1702. doi:10.1134/S0036023608110053

[36] Sergienko, V.S.; Minacheva, L.K.; Churakov, A.V. (2010) Specific features of the structure of germanium(IV) complexes with polybasic acids. Russian Journal of Inorganic Chemistry, 55 (13): 2001-2030. doi:10.1134/ S0036023610130012

[37] Rathore, N.S.; Leopold, A.; Pabby, A.K.; Fortuny, A.; Coll, M.T.; Sastre, A.M. (2009) Extraction and permeation studies of $\mathrm{Cd}(\mathrm{II})$ in acidic and neutral chloride media using Cyanex 923 on supported liquid membrane. Hydrometallurgy, 96 (1): 81-87. doi:10.1016/j.hydromet.2008.08.009

[38] Ruhela, R.; Panja, S.; Sharma, J.N.; Tomar, B.S.; Tripathi, S.C.; Hubli, R.C.; Suri, A.K. (2012) Facilitated transport of $\mathrm{Pd}(\mathrm{II})$ through a supported liquid membrane (SLM) containing $\mathrm{N}, \mathrm{N}, \mathrm{N}^{\prime}, \mathrm{N}^{\prime}$-tetra -(2-ethylhexyl) thiodiglycolamide T(2EH)TDGA: A novel carrier. Journal of Hazardous Materials, 229-230: 66-71. doi:10.1016/j.jhazmat.2012.05.064

[39] Ruhela, R.; Sharma, J.N.; Hubli, R.C.; Suri, A.K.; Tomar, B.S.; Panja, S.; Tripathi, S.C. (2010) N,N,N', N'-tetra(2-ethylhexyl) thiodiglycolamide T(2EH) TDGA A novel ligand for the extraction of palladium from high level liquid waste (HLLW). Radiochimica Acta, 98(4): 209-214.

[40] Marchese, J.; Valenzuela, F.; Basualto, C.; Acosta, A. (2004) Transport of molybdenum with Alamine 336 using supported liquid membrane. Hydrometallurgy, 72 (3): 309-317. doi:10.1016/j.hydromet.2003.07.003

[41] Hiss, T.G.; Cussler, E.L. (1973) Diffusion in high viscosity liquids. AIChE Journal, 19 (4): 698-703. doi:10.1002/(ISSN)1547-5905

[42] Arroyo, F.; Fernández-Pereira, C.; Olivares, J.; Coca, P. (2009) Hydrometallurgical recovery of germanium from coal gasification fly ash: pilot plant scale evaluation. Industrial \& Engineering Chemistry Research, 48 (7): 3573-3579. doi:10.1021/ie800730h

[43] Yang, X.; Duan, H.; Shi, D.; Yang, R.; Wang, S.; Guo, H. (2015) Facilitated transport of phenol through supported liquid membrane containing bis(2-ethylhexyl) sulfoxide (BESO) as the carrier. Chemical Engineering and Processing: Process Intensification, 93: 79-86. doi:10.1016/j.cep.2015.05.003

[44] Alumaa, P.; Pentchuk, J. (1998) Ionic strength dependence of heavy metal tartrate complex stabilities. Chromatographia, 47 (1): 77-80. doi:10.1007/ BF02466789
[45] Lin, F.H.-J.; Horváth, C. (1992) Measurement of stability constants for complexes of divalent cations with tartaric acid by ion chromatography. Journal of Chromatography A, 589 (1): 185-195. doi:10.1016/ 0021-9673(92)80021-L

[46] Chakrabarty, K.; Saha, P.; Ghoshal, A.K. (2010) Simultaneous separation of mercury and lignosulfonate from aqueous solution using supported liquid membrane. Journal of Membrane Science, 346 (1): 37-44. doi:10.1016/j.memsci.2009.09.010

[47] Zaheri, P.; Abolghasemi, H.; Ghannadi Maraghe, M.; Mohammadi, T. (2015) Intensification of Europium extraction through a supported liquid membrane using mixture of D2EHPA and Cyanex272 as carrier. Chemical Engineering and Processing, 92: 18-24. doi:10.1016/j.cep.2015.03.004

[48] Zheng, H.-D.; Wang, B.-Y.; Wu, Y.-X.; Ren, Q.-L. (2009) Instability mechanisms of supported liquid membranes for copper (II) ion extraction. Colloids and Surfaces A: Physicochemical and Engineering Aspects, 351 (1): 38-45. doi:10.1016/j.colsurfa.2009.09.028

[49] Duan, H.; Wang, S.; Yang, X.; Yuan, X.; Zhang, Q.; Huang, Z; Guo, H. (2017) Simultaneous separation of copper from nickel in ammoniacal solutions using supported liquid membrane containing synergistic mixture of M5640 and TRPO. Chemical Engineering Research and Design, 117: 460-471. doi:10.1016/j.cherd.2016.11.003

[50] Adnan, S.; Hoang, M.; Wang, H.; Xie, Z. (2012) Commercial PTFE membranes for membrane distillation application: effect of microstructure and support material. Desalination, 284: 297-308. doi:10.1016/j. desal.2011.09.015

[51] Camacho, L.M.; Dumée, L.; Zhang, J.; Li, J.-D.; Duke, M.; Gomez, J.; Gray, S. (2013) Advances in membrane distillation for water desalination and purification applications. Water, 5 (1): 94-196. doi:10.3390/w5010094

[52] Khayet, M.; Velázquez, A.; Mengual, J.I. (2004) Modelling mass transport through a porous partition: effect of pore size distribution. Journal of NonEquilibrium Thermodynamics, 29 (3): 279-299. doi:10.1515/JNETDY.2004.055

[53] Khayet, M.; Mengual, J.I.; Zakrzewska-Trznadel, G. (2005) Direct contact membrane distillation for nuclear desalination. Part I: review of membranes used in membrane distillation and methods for their characterisation. International Journal of Nuclear Desalination, 1 (4): 435-449. doi:10.1504/ IJND.2005.007020

[54] Panja, S.; Ruhela, R.; Misra, S.; Sharma, J.; Tripathi, S.; Dakshinamoorthy, A. (2008) Facilitated transport of Am (III) through a flat-sheet supported liquid membrane (FSSLM) containing tetra (2-ethyl hexyl) diglycolamide (TEHDGA) as carrier. Journal of Membrane Science, 325 (1): 158-165. doi:10.1016/j. memsci.2008.07.019

[55] Staszak, K.; Wojciechowska, A.; Reis, M.T.A.; Wojciechowska, I.; Wieszczycka, K.; Ismael, M.R.C.; Carvalho, J.M.R. (2017) Recovery of zinc(II) from chloride solutions using pseudo-emulsion based hollow fiber strip dispersion with pyridineketoxime 
extractants. Separation and Purification Technology, 177: 152-160. doi:10.1016/j.seppur.2016.12.046

[56] Manna, M.S.; Saha, P.; Ghoshal, A.K. (2014) Separation of medicinal catechins from tea leaves
(Camellia sinensis) extract using hollow fiber supported liquid membrane (HF-SLM) module. Journal of Membrane Science, 471: 219-226. doi:10.1016/j. memsci.2014.08.011 